
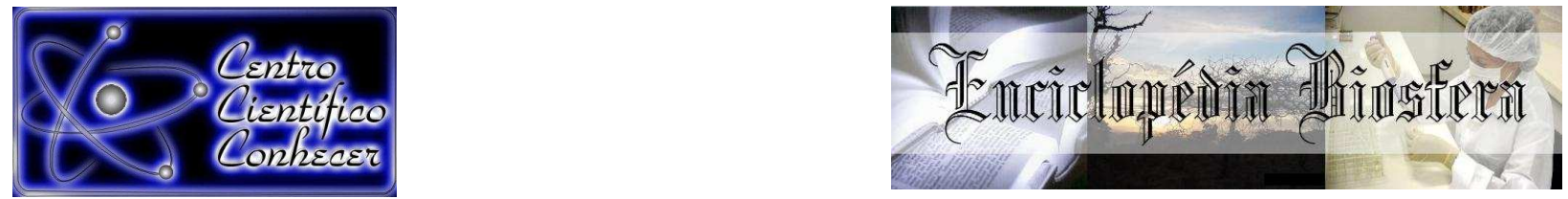

\title{
AVALIAÇÃO FÍSICO-QUÍMICA DAS LINGÜIÇAS FRESCAL E DEFUMADA DE CARNE DE SUÍNOS ALIMENTADOS COM DIFERENTES NÍVEIS DE INCLUSÃO DA TORTA DE LICURÍ
}

Fúlvio Viegas Santos Teixeira de Melo ${ }^{1,}$, Damião Bonfim Mendes $^{2}$, Manoel Adriano da Cruz Neto ${ }^{3}$, lumi da Silva Toyosumi ${ }^{4}$, Antonio Ramires Lyra Souza ${ }^{3}$

1. Professor do Instituto Federal de Educação Ciência e Tecnologia Baiano (fulviovstmelo@yahoo.com.br)

2. Graduando em Engenharia Agronômica da Universidade do Estado da Bahia

3. Graduando em Licenciatura em Ciências Agrárias do Instituto Federal de

Educação Ciência e Tecnologia Baiano

4. Graduando em Engenharia Agronômica da Universidade Federal do Recôncavo da Bahia

Recebido em: 08/09/2015 - Aprovado em: 14/11/2015 - Publicado em: 01/12/2015 DOI: http://dx.doi.org/10.18677/Enciclopedia_Biosfera_2015_101

\section{RESUMO}

Vinte e oito suínos mestiços (Landrace $X$ Duroc $X$ Pietrain) com peso médio de $30,75 \mathrm{Kg}$, foram submetidos a quatro tratamentos com dietas contendo diferentes níveis de inclusão da torta de Licurí (0;15; 30 e 45\%). O Presente trabalho teve como objetivo avaliar a composição físico-química da linguiça defumada e frescal elaborada com carne de suínos alimentados com diferentes níveis de inclusão da torta de licurí na ração. Após abate foram separados os pernis dos suínos e em seguida foi feita a desossa. Após a desossa os pernis dos suínos foram limpos (sem pele e gordura aparente) e estocados sob temperatura de aproximadamente $4^{\circ} \mathrm{C}$ juntamente com o toucinho sem pele. As análises físico-químicas foram realizadas em triplicata, sendo a proteína determinada pelo método de micro Kjedahl, os lipídios pelo método de Bligh e Dyer (1959), já os teores de umidade e cinzas foram realizadas de acordo com a metodologia descrita pela A.O.A.C - Association Of Official Analytical Chemists. Foi admitido um delineamento experimental inteiramente casualizado contendo quatro tratamentos (níveis de inclusão da torta de licurí na ração) com três repetições. Foi realizada analise de variância e para comparação das médias foi utilizado teste de Tukey a $1 \%$ de probabilidade. Para a realização da análise estatística foi utilizado o software SISVAR. Foram encontradas diferenças significativas $(p<0,01)$ entre os tratamentos utilizados nos dois tipos de linguiça avaliadas.

PALAVRAS-CHAVE: alimento alternativo, agregação de valor, tecnologia de alimentos.

\section{ASSESSMENT OF PHYSICOCHEMICAL FRESH PORK SAUSAGE AND PORK MEAT DEFUMDA FED WITH DIFFERENT LEVELS OF INCLUSION PIE LICURI}

\section{ABSTRACT}

Twenty-eight crossbred pigs (Landrace $\mathrm{x}$ Duroc $\mathrm{x}$ Pietrain) with an average weight of $30.75 \mathrm{~kg}$, were subjected to four treatments with diets containing different levels of 
inclusion of Licuri pie $(0,15,30$ and $45 \%)$. The present study aimed to evaluate the physical and chemical composition of smoked and fresh sausages made with pork meat fed with different levels of inclusion of Licuri pie in the feed. After slaughter were separated the hind legs of pigs and then was made boning. After boning the hind legs of pigs were clean (without skin and visible fat) and stored at a temperature of about $4^{\circ} \mathrm{C}$ along with the bacon without skin. The physico-chemical analyzes were performed in triplicate, and the protein determined by the micro method Kjeldahl, lipids by Bligh and Dyer method (1959), since the moisture and ash content were performed according to the methodology described by AOAC - Association of Official Analytical Chemists. A completely randomized experimental design was admitted containing 4 treatments (inclusion levels of Licuri pie in the feed) with three replications. Analysis of variance was performed to compare the means and was used Tukey test at $1 \%$ probability for statistical analysis was used SISVAR software. There were significant differences $(p<0.01)$ between the treatments evaluated in both types of sausage.

KEYWORDS: alternative food, technology foods, value aggregation.

\section{INTRODUÇÃO}

A melhoria na rentabilidade da carne suína está atrelada aos custos operacionais mais baixos, indústria beneficiadora e o produtor rural, sendo a combinação destes fatores o maior responsável pelo preço acessível da carne (MOURA et al. 2015)

O milho e a soja são os principais alimentos que compõem as rações dos animais não ruminantes, e nos últimos anos, têm sofrido aumentos sequenciais, o que pode inviabilizar a produção. A substituição parcial destes alimentos é uma saída para diminuir os custos da produção no que se refere à ração, no entanto, deve-se observar alguns fatores como a ecologia, aspectos econômicos, cultural e social, antes de adotar qualquer alternativa que seja, além disso, deve-se atentar para o fator nutricional, e atender as exigências dos animais. (MARTINS et al., 2012).

Segundo MELO et al. (2013), a torta de licurí é um subproduto do fruto do licurizeiro que tem se destacado como um excelente substituto parcial do milho e da soja na alimentação de suínos. Conforme afirma CREPALDI et al. (2001) a composição da amêndoa do licuri, ao qual é extraído o óleo, contêm em torno de: $49,2 \%$ de lipídeos, $11,5 \%$ de proteínas e 9,7\% de carboidratos totais.

Os embutidos aumentam a vida de prateleira das carnes propiciando a diversidade dos produtos, proporciona melhor aproveitamento para os produtores, otimizando a oferta de derivados. De acordo com BRASIL (2000), entende-se por linguiça o produto cárneo industrializado, obtido de carnes de animais de açougue, adicionados ou não de tecidos adiposos, ingredientes, embutido em envoltório natural ou artificial, e submetido ao processo tecnológico adequado.

A lingüiça é um produto que tem grande aceitação no mercado consumidor brasileiro e tem contribuído para melhorar a qualidade alimentar da crescente população mundial. Segundo MELO FILHO et al. (2004) o consumo de produtos cárneos curados é frequente em nosso país, principalmente pelo fato destes representarem uma fonte de alimentação rápida, de fácil acessibilidade e de que possuírem vida de prateleira longa se comparada a outras fontes de proteína animal, dentre esses produtos destaca-se principalmente a linguiça como sendo um dos mais acessíveis e populares, devido especialmente ao baixo custo. 
As linguiças suínas apresentam sabores marcantes que sempre atraem os consumidores, a linguiça produzida de suínos alimentados com níveis crescentes de torta de licurí pode ser uma excelente opção para agregar ainda mais valor e sabor ao produto. O presente trabalho teve como objetivo avaliar a composição físicoquímica da linguiça defumada e frescal elaborada com carne de suínos alimentados com diferentes níveis de inclusão da torta de licurí na ração.

\section{MATERIAL E MÉTODOS}

Os suínos foram criados no setor de suinocultura do Instituto Federal de Educação Ciência e Tecnologia Baiano, Campus Senhor do Bonfim, e foram alimentados com diferentes níveis de inclusão da torta de licurí $(0 ; 15 ; 30$ e 45\% de inclusão na ração) desde a fase inicial até o abate. Após abate foram separados os pernis dos suínos e em seguida foi feita a desossa. Após a desossa os pernis foram limpos (sem pele e gordura aparente) e estocadas sob temperatura de aproximadamente $4^{\circ} \mathrm{C}$ juntamente com o toucinho sem pele. Em seguida, a carne foi moída simultaneamente em moedor marca Super Mix Anodilar, equipado com disco de $8 \mathrm{~mm}$, e posteriormente foi colocada em bandeja para adição dos ingredientes, sendo manualmente bem misturada.

Após a incorporação dos ingredientes, as massas das lingüiças foram acondicionadas em bandejas, devidamente identificadas, tampadas e colocadas para curar por 48 horas, sob refrigeração $\left(\sim 4^{\circ} \mathrm{C}\right)$. Posteriormente foram embutidas em tripa artificial de médio calibre $(\sim 30 \mathrm{~mm})$, acondicionadas em sacos plásticos e refrigeradas $\left(\sim 4^{\circ} \mathrm{C}\right)$ até $\mathrm{o}$ momento das análises. Para a confecção da linguiça frescal foram utilizados $90 \%$ de carne, $10 \%$ de gordura, $1 \%$ de condimento para linguiça frescal, $1,5 \%$ de sal, $0,3 \%$ de sal de cura, $0,2 \%$ de fixador de cor, $0,2 \%$ de alho desidratado, $0,2 \%$ de cebola desidratada e $5 \%$ de água gelada, já para a linguiça defumada foram utilizados $90 \%$ de carne, $10 \%$ de gordura, $1 \%$ de condimento califórnia, $1,5 \%$ de sal, $0,3 \%$ de sal de cura, $0,2 \%$ de fixador de cor, $0,2 \%$ de alho desidratado, $0,2 \%$ de cebola desidratada e $5 \%$ de água gelada.

As análises físico-químicas foram realizadas em triplicata, sendo a proteína determinada pelo método de micro Kjedahl, os lipídios pelo método de BLIGH \& DYER (1959), já os teores de umidade e cinzas foram realizadas de acordo com a metodologia descrita pela A.O.A.C - Association Of Official Analytical Chemists.

Foi admitido um delineamento experimental inteiramente casualizado contendo quatro tratamentos (níveis de inclusão da torta de licurí na ração) com três repetições para cada linguiça. Foi realizada análise de variância e para comparação das médias foi utilizado teste de Tukey a 1\% de probabilidade. Para a realização da análise estatística foi utilizado o software SISVAR.

\section{RESULTADOS E DISCUSSÃO}

Foram encontradas diferenças significativas $(p<0,01)$ para as variáveis lipídio e cinzas, já para as variáveis proteína e umidade os resultados não foram significativos $(p>0,01)$ na avaliação realizada nas linguiças defumadas. Pode-se observar que o tratamento onde houve a inclusão de $30 \%$ da torta de licurí na ração dos suínos obteve o melhor resultado para a variável lipídio, mesmo não diferindo estatisticamente dos tratamentos onde foram incluídos 15 e $45 \%$ da torta de licurí na ração dos animais, sendo o menor teor encontrado para o tratamento onde não houve a inclusão da torta de licurí na ração, desta forma, podemos inferir que a torta de licurí exerce influencia na incorporação de lipídios no tecido muscular dos suínos 
que foram alimentados com este produto e nos produtos elaborados a partir desta matéria prima.

Os resultados encontrados para a variável cinzas também mostram variação, e é observado o melhor resultado para o nível de inclusão em 30\% da torta de licurí na ração dos suínos. Mesmo não havendo diferença significativa os teores de proteína entre os tratamentos variaram de 13,76 a $14,94 \%$, os teores de umidade variaram de 51,39 a 55,07\%. A relação entre os teores de lipídios e umidade das amostras analisadas foram inversamente proporcionais. Os resultados encontrados na avaliação físico-química da linguiça defumada estão na tabela 2.

TABELA 2. Composição físico-química da linguiça defumada elaborada com carne de suínos alimentados com diferentes níveis de inclusão da torta de licurí.

\begin{tabular}{lcccccc}
\hline \multirow{2}{*}{ Composição (\%) } & \multicolumn{7}{c}{ Tratamentos } \\
\cline { 2 - 7 } & $0 \%$ & $15 \%$ & $30 \%$ & $45 \%$ & CV(\%) & Valor-P \\
\hline Proteína & $14,49^{\mathrm{a}}$ & $13,76^{\mathrm{a}}$ & $14,09^{\mathrm{a}}$ & $14,94^{\mathrm{a}}$ & 4,44 & 0,1998 \\
Lipídio & $17,67^{\mathrm{b}}$ & $22,90^{\mathrm{ab}}$ & $24,90^{\mathrm{a}}$ & $22,95^{\mathrm{ab}}$ & 7,71 & 0,0029 \\
Umidade & $55,07^{\mathrm{a}}$ & $54,19^{\mathrm{a}}$ & $51,39^{\mathrm{a}}$ & $54,56^{\mathrm{a}}$ & 4,47 & 0,3082 \\
Cinzas & $2,44^{\mathrm{ab}}$ & $2,39^{\mathrm{b}}$ & $2,73^{\mathrm{a}}$ & $2,06^{\mathrm{c}}$ & 3,71 & 0,0001 \\
\hline
\end{tabular}

Letras diferentes em uma mesma linha indicam diferença estatística. (Tukey a 1\%).

NERES et al. (2014), analisando lingüiça defumada elaborada com carne de búfalos encontraram resultados semelhantes para as variáveis lipídio e cinzas sendo que as amostras diferiram entre si $(\mathrm{P}<0,05)$, já para a variável proteína os resultados diferiram do presente trabalho, pois o mesmo encontrou diferenças significativas para proteína $(P<0,05)$, enquanto que na presente pesquisa não houve diferenças significativas para esta variável.

Quanto ao valor de umidade o maior valor encontrado no presente estudo $54,56 \%$ se assemelha aos valores médios encontrado por BORDIGNON et al. (2010), de 57,93 e 57,84\% que avaliou a elaboração de croquete de tilápia do Nilo (Oreochromis niloticus) a partir de CMS e aparas do corte em ' $V$ ' do filé, corroborando com a presente pesquisa não encontraram diferenças significativas para umidade.

Para a linguiça frescal foram observadas diferenças significativas $(p<0,01)$ para as variáveis proteína, lipídio e cinzas, não sendo observada diferença $(p>0,01)$ para a variável umidade. A partir dos resultados encontrados nas análises pode-se inferir que para a variável proteína o melhor resultado foi para o nível de inclusão em $45 \%$ não tendo diferença estatística com o nível em 15\%, pode-se inferir também que o menor resultado foi para o nível em 30\%. O teor de lipídio apresentou os maiores valores para os tratamentos com 15 e $45 \%$ de inclusão da torta de licurí na ração dos animais, não diferindo entre estes tratamentos, sendo os menores valores para os tratamentos com 0 e $30 \%$ de inclusão da torta.

Os teores observados de cinzas para a linguiça frescal variaram de 1,96 a $2,66 \%$, sendo os maiores valores encontrados para o tratamento com $45 \%$ de inclusão da torta sendo que este tratamento não diferiu estatisticamente dos tratamentos com 0 e $15 \%$ de inclusão da torta, sendo os menores valores encontrados para o nível de inclusão em $30 \%$ da torta na ração. Mesmo não havendo diferença estatística para a variável umidade, pode-se obervar que a sua 
variação dentro dos tratamentos foi inversamente proporcional aos teores de lipídios encontrados nas análises.

TABELA 3. Composição físico-química da linguiça frescal elaborada com carne de suínos alimentados com diferentes níveis de inclusão da torta de licurí.

\begin{tabular}{|c|c|c|c|c|c|c|}
\hline \multirow{2}{*}{ Composição (\%) } & \multicolumn{4}{|c|}{ Tratamentos } & \multirow[b]{2}{*}{ CV $(\%)$} & \multirow[b]{2}{*}{ Valor-P } \\
\hline & $0 \%$ & $15 \%$ & $30 \%$ & $45 \%$ & & \\
\hline Proteína & $14,05^{b c}$ & $15,37^{\mathrm{ab}}$ & $12,87^{c}$ & $17,64^{a}$ & 4,25 & 0,0001 \\
\hline Lipídio & $10,23^{b}$ & $10,30^{b}$ & $14,78^{\mathrm{a}}$ & $13,85^{\mathrm{a}}$ & 8,00 & 0,0007 \\
\hline Umidade & $65,66^{a}$ & $65,47^{a}$ & $63,53^{a}$ & $62,36^{a}$ & 2,08 & 0,0460 \\
\hline Cinzas & $2,43^{\mathrm{ab}}$ & $2,23^{\mathrm{ab}}$ & $1,96^{b}$ & $2,66^{\mathrm{a}}$ & 6,91 & 0,0040 \\
\hline
\end{tabular}

NASCIMENTO et al. (2012), avaliando as características físico-químicas de lingüiças frescais elaboradas com carne de avestruz encontraram resultados diferentes para as variáveis proteína e lipídeos, sendo que suas formulações não apresentaram diferença significativa entre si, já para a variável umidade os resultados foram semelhantes aos resultados encontrados na presente pesquisa. Ainda concernente a variável umidade, CAVALHEIRO et al. (2010) analisando as características físico-químicas de embutido curado fermentado com adição de carne de avestruz associada à de suíno, encontraram resultados diferentes aos encontrados no presente trabalho pois os mesmos encontraram diferença significativa $(P<0,05)$ em todos os tratamentos estudados. Os valores de cinzas estão abaixo dos encontrados por SILVA et al. (2013), que analisando lingüiça frescal mista de carne suína e caprina encontraram valor médio de 3,46\% para cinzas. Os valores de cinzas estão numa media padrão no presente estudo, segundo NASCIMENTO et al. (2012), esses valores podem aumentar devido à utilização de cloreto de sódio, sais de cura (nitrito), condimentos e especiarias na formulação das linguiças.

\section{CONCLUSÃO}

A torta farelada de licurí utilizada na ração de suínos exerce influencia na composição química dos embutidos (linguiça frescal e defumada) aumentando os teores de lipídios e proteínas, sendo indicados os níveis de 30 e $45 \%$ inclusão da torta de licurí na ração dos suínos.

\section{REFERÊNCIAS}

BORDIGNON, A. C.; SOUZA, B. E.; BOHNENBERGER, L.; HILBIG, C. C.; FEIDEN A. E BOSCOLO, W. R. Elaboração de croquete de tilápia do Nilo (Oreochromis niloticus) a partir de CMS e aparas do corte em „V do filé e sua avaliação físicoquímica, microbiológica e sensorial. Acta Scientiarum. Animal Sciences, Maringá, v.32, n.1, p. 109-116, 2010.

BLIGH, E. G.; DYER, W. J. A rapid method of total lipid extraction and purification.

Cand. J. Biochemistry Physiology, v.37, n.8, p.911-917, 1959. 
BRASIL. Instrução Normativa no 4 de 31 de março de 2000. Anexo - Regulamento Técnico de Identidade e Qualidade de Linguiça. Ministério da Agricultura, 2000.

CAVALHEIRO, C.P., TERRA, N.N., FRIES, L.L.M., MILANI, L.I.G., REZER, A.P.S., CAVALHEIRO, C.V., MANFIO, M. Características físico-químicas de embutido curado fermentado com adição de carne de avestruz associada à de suíno. Ciência Rural, Santa Maria, v.40, n.2, p.447-452, fev, 2010.

CREPALDI, I.C.; MURADIAN, L.B.A.; RIOS, M.D.G.; PENTEADO, M.V.C. E SALATINO, A. 2001. Composição nutricional do fruto de licuri (Syagrus coronata (Martius) Beccari). Revta Brasil. Bot., São Paulo, v.24, n.2, p.155-159.2001.

MARTINS, F. M., SANTOS FILHO, J. I., SANDI, A. J., MIELE, M., LIMA, G. J. M. M., BERTOL, T. M., AMARAL, A. L., MORES, N., KICH, J. D., DALLA COSTA, O. A., Coeficientes para cálculos do custo de produção de suínos. Embrapa Suínos e Aves, Comunicado técnico, 506, p.10, 2012.

MELO FILHO, J. F. B; BISCONTINI, T. M. B; ANDRADE, S. A. Níveis de nitrito e nitrato em salsichas comercializadas na região metropolitana do recife. Ciência $\mathbf{e}$ Tecnologia de Alimentos, Campinas, v.24, n.3, p. 390-392, jul. /set. 2004.

MELO, F.V.S.T., MENDES, D.B., NETO, M.A.C., Toyosumi, I.S., Ricardo Duarte Abreu, R.D., Substituição do farelo de soja pela torta de licurí (Syagrus coronata) na alimentação de suínos na fase de crescimento e terminação. Enciclopédia biosfera, Centro Científico Conhecer - Goiânia, v.9, n.16; p. 19912013.

MOURA, J.W.F, MEDEIROS, F.M., ALVES, M.G.M., BATISTA A.S.M., Fatores influenciadores na carne suína. Revista científica de produção animal, v.17, n.1, p 18-29, 2015.

NASCIMENTO, R.S., FONSECA, A.B.M., FRANCO, R.M., MIRANDA, Z.B. Linguiças frescais elaboradas com carne de avestruz: características físico-químicas. Ciência Rural, Santa Maria, v.42, n.1, p.184-188, jan, 2012.

NERES, L.S., PACHECO, E.A., JÚNIOR, J.B.L., JOELE, M.R.S.P., Lingüiça defumada elaborada com carne de búfalos caracterização físico-química, microbiológica e sensorial. Revista Brasileira de Produtos Agroindustriais, Campina Grande, v.16, n.3, p.273-278, 273, 2014.

SILVA, D.P., SILVA, T.S., SILVA, A.D.P., JUNIOR, A.F.C., Gessiel Newton Scheidt, G.N. Análise físico-química e sensorial de linguiça frescal mista de carne suína e caprina. Revista Verde (Mossoró - RN), v.8, n.3, p. 239 - 246, Jul - Set, 2013. 